\title{
Estratégias para incentivar o transporte não motorizado em megaeventos esportivos: o caso do estádio do Maracanã, Rio de Janeiro
}

\author{
Strategies to promote non-motorized transportation in major sporting events: \\ the case of Maracanã stadium, Rio de Janeiro
}

Josefina Flórez ${ }^{[0]}$, Licinio da Silva Portugal ${ }^{[b]}$, Nathaly Escobar ${ }^{[b]}$

\begin{abstract}
[a] Universidad Simón Bolívar (USB), Departamento de Planificación Urbana, Caracas, Venezuela
[b] Universidade Federal do Rio de Janeiro (UFRJ), Instituto Alberto Luiz Coimbra de Pós-graduação e Pesquisa em Engenharia (COPPE), Programa de Engenharia de Transportes (PET), Rio de Janeiro, RJ, Brasil
\end{abstract}

\section{Resumo}

A fim de contribuir com a concepção de políticas de mobilidade urbana mais eficientes, foram definidas e avaliadas estratégias para promover o transporte não motorizado (principalmente a pé) nos jogos realizados no estádio do Maracanã, que possam ser replicáveis em outras instalações esportivas que fazem parte dos megaeventos no Rio de Janeiro. As estratégias foram formuladas com base em duas fontes de informações, na revisão bibliográfica e nos resultados de uma pesquisa de campo constituída por: mais de 1.000 entrevistas com os espectadores dos jogos no Maracanã durante a Copa das Confederações de Futebol 2013; grupos focais envolvendo frequentadores desse estádio; e entrevistas em profundidade. Posteriormente, especialistas da administração pública foram consultados e avaliaram tais estratégias, definindo como prioritárias aquelas referentes às melhorias na infraestrutura e nos equipamentos para pedestres e cadeirantes, bem como as campanhas de divulgação e de conscientização que incentivam o uso dos modos não motorizados e desestimulam o uso dos automóveis. As estratégias destacadas pelos especialistas se caracterizam por apresentar um menor nível de dificuldade e de custo para a sua implantação, representando uma boa opção para melhorar a qualidade urbana e promover a mobilidade sustentável.

Palavras-chave: Estratégias de transporte. Transporte não motorizado. Caminhada. Bicicleta.

Megaeventos esportivos.

\section{Abstract}

Strategies to promote non-motorized transport (mainly on foot) are defined and evaluated in the games held at the Maracanã stadium. The strategies are formulated based on bibliographical review, and on the results of a field research comprising more than 1,000 interviews with spectators of the 2013 FIFA Confederations Cup games at the Maracanã, focus groups with stadium attendants, and in-depth interviews. Subsequently,

JF é urbanista, Doutora Engenheira de Caminhos, Canais e Portos, e-mail: jflorez@usb.ve LSP é engenheiro civil, Doutor em Engenharia de Produção, e-mail: licinio@pet.coppe.ufrj.br NE é urbanista, Especialista MBA em Marketing, e-mail: escobar.nathaly@gmail.com 
public administration specialists evaluated the strategies and prioritized those related to improvements to infrastructure and facilities for pedestrians and people in wheelchairs, as well as dissemination and awareness campaigns to promote more sustainable transport alternatives. The strategies highlighted by the specialists are characterised by lower levels of complexity and cost of implementation, representing a good option to improve urban quality and promote sustainable mobility. These strategies are expected to be replicated in other sports facilities hosting mega-events in Rio de Janeiro.

Keywords: Transport strategies. Non-motorised transport. Walking. Bicycle. Mega-events.

\section{Introdução}

A ocorrência de megaeventos nas cidades representa diversos desafios para a administração pública, como o gerenciamento do grande número de pessoas atraídas e os impactos significativos que elas geram no sistema de transporte, em razão das altas demandas de viagens concentradas em um breve período de tempo, devendo o sistema de transporte garantir a mobilidade efetiva de bens e de pessoas com necessidades cotidianas e temporais (Parkes et al., 2016).

Comumente nesses eventos, o planejamento e o gerenciamento da mobilidade se fundamentam em estratégias destinadas a incentivar o uso do transporte público (TP) e a restringir o uso do automóvel. Entretanto, observa-se uma menor atenção dada aos modos não motorizados (MNM), apesar de que eles são uma atraente alternativa quando os eventos se realizam em contextos urbanos que permitem viagens de curta a média distância (Portugal et al., 2014).

Além disso, as viagens em MNM integradas a outros modos motorizados são expressivas, considerando que a caminhada, comumente, está presente no início e no final dos deslocamentos, representando um elo de conexão modal (LTNZ, 2009; Rietveld, 2000). Somente nas últimas duas décadas, têm-se incrementado as políticas dirigidas a promover os MNM em razão dos evidentes efeitos positivos destes em termos de favorecer o ambiente, de ser econômico, de dar suporte à economia local, de incrementar a percepção de segurança e de melhorar a saúde pública (Banco Mundial, 2002; Rodrigues et al., 2014). Essa mudança de enfoque, valorizando o papel dos MNM, constitui um desafio na formulação das estratégias de transporte (Malhado \& Rothfuss, 2013), o que contrasta com os tímidos avanços observados em cidades brasileiras (Flórez et al., 2014). Em tal contexto, autores, como Stott et al. (2006), têm procurado entender o comportamento dos usuários em megaeventos.
Mais recentemente, Parkes et al. (2016) estudaram a mudança no comportamento das viagens dos indivíduos quanto à mobilidade cotidiana nos Jogos Olímpicos e Paraolímpicos (JJ00) de Londres 2012. Eles apontaram que houve redução no número das viagens, além de alterações nos horários, nos modos e nas rotas. Mudança nos padrões de viagens também foi observada em evento realizado no Rio de Janeiro (Portugal et al., 2014). Entretanto, em Londres, 6\% mantiveram o novo comportamento após os jogos, mostrando que os megaeventos representam uma oportunidade para promover estratégias que incentivem e incorporem comportamentos de mobilidade sustentável. No caso da mudança modal, requer-se que a nova alternativa ofereça condições comparativas que sejam percebidas pelos usuários e favoreçam a sua escolha (Parkes et al., 2016). Bovy (2007) expõe que um dos aspectos cruciais do serviço e da infraestrutura do transporte em megaeventos é o estádio e o seu entorno, em um raio de $1 \mathrm{~km}$, no qual se concentram viagens a pé e diferentes modalidades de acesso.

Nesse sentido, cresce a exigência pela disponibilização de serviços adequados para garantir um transporte de qualidade tanto para os turistas como para os moradores, segundo a noção de legado (Portugal et al., 2014). No entanto, o estádio de futebol do Maracanã como outros equipamentos esportivos da cidade localizam-se em bairros que permitem acesso a pé ou por bicicleta, sendo possível promover os MNM durante futuros megaeventos, assim como favorecer o acesso ao TP com medidas que permitam melhorar a qualidade dos trajetos a pé entre as estações e paradas de TP e as instalações esportivas.

A fim de contribuir com a concepção de políticas de mobilidade mais eficientes, neste artigo foram definidas e avaliadas estratégias para promover o transporte não motorizado nos jogos realizados no estádio do Maracanã. As estratégias foram formuladas com base na revisão bibliográfica e nos resultados 
de uma pesquisa de campo formada por: mais de 1.000 entrevistas com os espectadores da Copa das Confederações FIFA em 2013 (CC2013); grupos focais realizados com frequentadores do estádio; e entrevistas em profundidade dirigidas a cadeirantes. Os resultados foram submetidos à avaliação de especialistas que trabalham na administração pública.

Deve-se ressaltar que existem poucos estudos sobre mobilidade em cidades brasileiras que consideram as atitudes e preferências dos usuários na escolha modal em megaeventos, assim como na literatura em geral (Malhado \& Rothfuss, 2013). Também são escassas as pesquisas sistematizadas e documentadas sobre experiências envolvendo a mobilidade em megaeventos no Rio de Janeiro, apesar do histórico dessa cidade em acolher grandes eventos (Rio de Janeiro, 2013), como os Jogos Pan-Americanos em 2007, a Copa do Mundo de Futebol FIFA em 2014 (CMF2014) e os JJ002016. Portanto, os resultados desta pesquisa contribuem para preencher uma parte desse vazio do conhecimento, ao levar em consideração as motivações dos usuários na sua escolha modal com ênfase nos MNM, assim como na definição de estratégias que consideram experiências prévias, valorização dos usuários e avaliação de especialistas.

0 artigo estrutura-se em cinco itens, incluindo esta introdução. No segundo item, apresenta-se o contexto em que se realiza a pesquisa e, no terceiro, descrevem-se as estratégias destinadas a promover os MNM, principalmente a caminhada, incluindo-se, de forma exploratória, os cadeirantes e os ciclistas. Por fim, apresentam-se os resultados da avaliação das estratégias pelos especialistas e as conclusões.

\section{Contexto da pesquisa}

Rio de Janeiro e Tijuca: contexto espacial da pesquisa

Na Região Metropolitana do Rio de Janeiro (RMRJ), realizam-se diariamente mais de 22 milhões de viagens (Rio de Janeiro, 2015), das quais cerca de 94\% ocorrem no espaço viário, o qual não dispõe de uma malha viária suficiente e especializada para atender a essa elevada demanda, bem como pela tendência de aumento da taxa de motorização (ODM, 2013). Como consequência, são frequentes os acidentes de trânsito, que afetam, principalmente, os usuários mais frágeis. Além disso, cerca de $60 \%$ das mortes no trânsito do Rio são por atropelamentos de pedestres e de ciclistas (Waiselfisz, 2013), o que indica a pouca atenção dada aos MNM.

Em tais condições, atender às necessidades de mobilidade geradas por um megaevento envolve certa complexidade, exigindo adequadas políticas públicas, como incentivar o uso da caminhada e da bicicleta. Entretanto, para o seu sucesso, é requerido que o entorno da instalação esportiva apresente condições seguras e favoráveis a tais modalidades.

No caso do estádio do Maracanã, ele se insere na Grande Tijuca, cujo ambiente construído é potencialmente indicado à utilização dos MNM, fruto do uso do solo denso e diverso, malha viária altamente conectada e infraestrutura destinada aos pedestres. Também para os ciclistas, ao situar-se na área que tem a maior extensão de ciclovias da cidade (81 km), além de uma conexão ao centro urbano, segundo dados de 2011 (Armazém de Dados, 2016; Rio de Janeiro, 2016). Vivem nessa área 456 mil habitantes, dos quais $12 \%$ têm nível de renda mais alto e compatível com o perfil do grupo-alvo do megaevento. Entretanto, apresenta uma taxa de motorização acima da média da cidade, o que sugere uma maior propensão ao uso do automóvel, reforçando a necessidade de políticas de restrição de acesso por essa modalidade.

\section{Pesquisa de campo durante a Copa das Confederações 2013}

Durante a CC2013, realizaram-se entrevistas nas imediações do estádio, aplicando três tipos de questionários a uma amostra dos espectadores dos três jogos realizados no Maracanã. Um questionário, identificado como "compacto", tratou das características pessoais dos usuários (idade, sexo, local de residência) e das características da viagem para acessar o estádio (origem e modalidade principal). Outro questionário, chamado "complementar", acrescentou perguntas sobre: a percepção da qualidade da viagem (em todas as modalidades), os motivos que justificaram a escolha do modo utilizado na viagem ou prevista para o próximo jogo. 0 terceiro questionário aplicou-se às pessoas que usavam cadeiras de roda, indagando-as adicionalmente sobre a percepção da qualidade da viagem e, especificamente, sobre a qualidade do trajeto 
realizado, desde o modo de transporte principal até o estádio.

Posteriormente, processaram-se os dados válidos, resultando em um total de 1.095 questionários compactos, 351 complementares e 17 dirigidos aos cadeirantes. Do total da amostra do questionário compacto, 7,43\% dos participantes realizaram sua viagem a pé (Tabela 1). Com relação ao questionário direcionado aos cadeirantes, ainda que pequena a amostra, é possível identificar os atributos de qualidade de serviço mais valorados pelos usuários.

Adicionalmente, foram utilizadas duas técnicas qualitativas: grupos focais e entrevistas em profundidade. A primeira permitiu explorar a percepção, as atitudes e o comportamento dos pedestres de forma mais detalhada. Essa técnica se aplica em grupos reduzidos de pessoas com certas características comuns e que fazem parte do público-alvo da pesquisa (Cruz et al., 2002). Com tal propósito, buscou-se aplicar em dois grupos com moradores nos bairros do entorno do Maracanã que tivessem assistido a algum evento no estádio depois de sua reforma (junho de 2013): um grupo envolvendo cinco jovens universitários (20-25 anos) e outro grupo de dez pessoas com mais de 25 anos. Com a realização do segundo grupo, foi possível ratificar as tendências observadas no primeiro e fundamentar a análise, alcançando os objetivos propostos. Já nas entrevistas em profundidade (Malhotra, 2012), exploraram-se individualmente, por

Tabela 1 - Distribuição modal das viagens com origem na Tijuca e em todas as localidades

\begin{tabular}{lcc}
\hline Modo de transporte & $\begin{array}{c}\text { Viagens com origem } \\
\text { na Tijuca (\%) }\end{array}$ & $\begin{array}{c}\text { Viagens com } \\
\text { origem em todas as } \\
\text { localidades (\%) }\end{array}$ \\
\hline Automóvel & 4,21 & 14,32 \\
Táxi & 10,53 & 7,43 \\
Coletivo de uso privado & 0 & 10,73 \\
Metrô & 8,42 & 45,17 \\
Trem & 2,10 & 5,01 \\
Ônibus & 3,16 & 9,82 \\
Não motorizados & 71,58 & 7,52 (*) \\
Total & 100,00 & 100,00 \\
\hline
\end{tabular}

${ }^{(*)}$ A pé $(7,43 \%)$ e por bicicleta $(0,09 \%)$.

Fonte: Elaboração própria com base no questionário compacto. meio de diálogo semiestruturado, as opiniões genuínas dos entrevistados. Foram realizadas sete entrevistas com cadeirantes e seis com especialistas dessa área. Ambas as técnicas permitiram obter informações detalhadas e valiosas que, posteriormente, foram processadas para complementar os resultados dos questionários aplicados.

Com relação aos resultados dos questionários, a região da Tijuca concentra a origem de todas as viagens a pé para acessar o Maracanã, devido às naturais limitações desse modal para percorrer longas distâncias. Ainda assim, quase $15 \%$ das viagens geradas nela realizaram-se por modos motorizados individuais (táxi e automóvel), apesar das restrições para estacionar (Tabela 1).

Vale mencionar que a proporção de viagens em bicicleta foi desprezível, o que impossibilitou considerar a opinião dos ciclistas. Porém, a pouca utilização dessa modalidade justifica um maior incentivo de seu uso nesses megaeventos. Já a proporção de viagens a pé reforça sua a importância como alternativa de transporte e a necessidade de ser incentivada. Em ambos os casos, o desafio é de contemplar adequadas estratégias derivadas das boas práticas disponíveis, mas, ao mesmo tempo, aderentes às especificidades locais, fruto das pesquisas de campo realizadas.

\section{Estratégias para incentivar o transporte não motorizado durante os jogos no Maracanã}

As estratégias propostas estão destinadas a incentivar os MNM, principalmente a caminhada, incluindo ações orientadas aos cadeirantes e aos ciclistas. Aquelas direcionadas a promover as viagens a pé foram elaboradas de acordo com os resultados obtidos nos questionários realizados durante a CC2013, nos grupos focais, assim como os derivados da revisão bibliográfica. Além disso, foram enfatizadas recomendações para a área da Tijuca, onde todas as viagens a pé se originaram. As estratégias destinadas a favorecer o acesso dos cadeirantes se sustentam, além do estado da arte, nos dados obtidos por meio das entrevistas em profundidade realizadas com eles e com os especialistas e dos resultados dos questionários. Já as recomendações para o incentivo da bicicleta foram definidas baseadas apenas na revisão bibliográfica. 
Desse processo derivaram-se 16 estratégias que, posteriormente, foram agrupadas em categorias, considerando a classificação proposta por America Walks \& Sam Schwartz Engineering (2012), com base em quatro áreas: desenho e engenharia (desenho, tráfego, elementos das interseções e sinalização envolvendo a infraestrutura e aspectos operacionais); uso do solo; promoção e educação; e aplicação das normativas. De acordo com a natureza e o alcance desta pesquisa e dos resultados obtidos em campo, destacaram-se os componentes da área de "desenho e engenharia" com ênfase nos pedestres, resultando em um total de cinco categorias: a primeira (A) englobou aquelas relacionadas às melhorias necessárias em termos de infraestrutura e de equipamentos destinados a pedestres e cadeirantes; a segunda (B) reuniu tais melhorias específicas da bicicleta; a terceira (C) abrangeu o conjunto de condições operacionais necessárias para uma melhor experiência dos pedestres; a quarta (D) agrupou o conjunto de ações orientadas a educar os potenciais usuários sobre as vantagens dos MNM; a quinta (E) compreendeu estratégias dirigidas ao uso do solo e à promoção da Tijuca como área de eventos e de zona turística devido ao seu potencial.

As estratégias encontram-se sumarizadas nas Tabelas 2 a 6 . Na primeira coluna de cada uma das referidas tabelas elas são definidas, e, na segunda, são indicados os resultados da pesquisa de campo, assim como as fontes bibliográficas que as sustentam.

\section{Estratégias destinadas a melhorar a infraestrutura e os equipamentos para pedestres e cadeirantes $(A)$}

Esta categoria compreendeu três estratégias que buscam favorecer um ambiente mais seguro e inclusivo, trajetos mais diretos e conexão entre os pontos de interesses e as paradas e estações de TP (Tabela 2).

Tabela 2 - Caracterização e justificativa das estratégias destinadas a melhorar a infraestrutura e os equipamentos para pedestres e cadeirantes

\begin{tabular}{|c|c|}
\hline Estratégia & Justificativa \\
\hline $\begin{array}{l}\text { A1. Desenvolver e implementar projetos seguros e de alta qualidade urbana para } \\
\text { pedestres nos principais trajetos ao Maracanãa, oriundos de diferentes geradores de } \\
\text { viagens a pé localizados na vizinhança, priorizando a linearidade do trajeto, de forma } \\
\text { a evitar potenciais interferências que possam prejudicar a acessibilidade e a rapidez da } \\
\text { caminhada dos pedestres. }\end{array}$ & $\begin{array}{l}\text { - Principais atributos para realizar as viagens a pé, segundo os entrevistados: rapidez, proximida- } \\
\text { de, facilidade, evitar confusão, ser divertido com o grupo e falta de estacionamento; } \\
\text { - Atributos mais valorizados estão associados à acessibilidade: rapidez (50\%); proximidade } \\
(38,5 \%) \text { e facilidade }(19,2 \%) \text {; } \\
\text { - Rapidez está relacionada com: ausência de obstáculos, existência de caminhos diretos, possibilida- } \\
\text { de de seleccãa de rotas mais curtas e baixo volume de pessoas (Flórez et al., 2014). }\end{array}$ \\
\hline $\begin{array}{l}\text { A2. Melhorar as condições de caminhabilidade no entorno, estendendo tais condições a } \\
\text { distâncias maiores, particularmente as superiores a } 750 \text { metros (cerca de } 10 \text { minutos } \\
\text { de caminhada) ou ainda } 1.500 \text { metros. }\end{array}$ & $\begin{array}{l}\text { - Os entrevistados que fazem a viagem toda a pé percebem uma menor qualidade dos trajetos } \\
\text { até o estádio do que aqueles que chegam em outras modalidades; } \\
\text { - } 0 \text { tipo e as características das calcadas são fatores relevantes que afetam a mobilidade dos } \\
\text { pedestres (Valenzuela-Montes \& Talavera-García, 2015). Os resultados das entrevistas mos- } \\
\text { tram que, quanto maior a proximidade ao estádio, melhor a percepção da qualidade, o que } \\
\text { está vinculado às remodelaç̃oes realizadas no entorno do Maracanã e à proibição do trânsito } \\
\text { de veículos nas imediaç̦ées; } \\
\text { - A arborização ao longo dos caminhos foi um aspecto bastante comentado nos grupos focais } \\
\text { e, de acordo com Valenzuela-Montes \& Talavera-García (2015), é um dos quatro fatores que } \\
\text { revelam maior significância na mobilidade dos pedestres. }\end{array}$ \\
\hline $\begin{array}{l}\text { A3. Favorecer a autonomia dos cadeirantes ou de pessoas com deficiência de mobilida- } \\
\text { de por meio de rotas sem obstáculos, com a existência de rampas dentro dos padrões } \\
\text { de desenho universal. Disponibilizar estacionamento preferencial aos cadeirantes com } \\
\text { acessos universais. }\end{array}$ & $\begin{array}{l}\text { - Atributos realçados pelos cadeirantes: acessibilidade, agradabilidade, autonomia, conforto, } \\
\text { conveniência e segurança; } \\
\text { - As piores avaliações de satisfaccão no entorno do estádio foram para autonomia e segurança; } \\
\text { - Para } 57 \% \text { dos entrevistados, a segurança urbana (atitudes antissociais) teve maior impor- } \\
\text { tância; } \\
\text { - Observou-se a inexistência de estacionamentos preferenciais destinados a cadeirantes no está- } \\
\text { dio, enquanto os disponíveis no entorno não contavam com rotas acessíveis até o Maracanã; } \\
\text { - A acessibilidade propicia as relações da sociedade, por isso o espaço urbano deve estar livre de } \\
\text { barreiras arquitetônicas e urbanas (Machado \& Lima, 2015). }\end{array}$ \\
\hline
\end{tabular}

Fonte: Elaboração própria. 
Tabela 3 - Caracterização e justificativa das estratégias destinadas a melhorar a infraestrutura e os equipamentos para bicicletas

\begin{tabular}{|c|c|}
\hline Estratégia & Justificativa \\
\hline $\begin{array}{l}\text { B1. Ampliar a rede de ciclovias na Tïuca, melhorando a qualidade e a } \\
\text { segurança da sua infraestrutura e integrando rotas com outros bairros } \\
\text { que se encontram a uma distância aceitável para realizar as viagens } \\
\text { de bicicleta. } \\
\text { B2. Instalar bicicletários e equipamentos seguros e adequados nas } \\
\text { imediações do estádio. }\end{array}$ & $\begin{array}{l}\text { - Observou-se, na pesquisa de campo e na bibliografia consultada (Scheiner, 2010, 2011), uma propensão } \\
\text { ao uso do automóvel ou do táxi em pessoas com maior nível de renda, como são os casos da Tïuca e da } \\
\text { Zona Sul, áreas com condiç̃̃es favoráveis ao uso de bicicleta; } \\
\text { - Usuários de TP tendem a não usar a bicicleta por: risco de uso, segurança urbana, trânsito perigoso e falta } \\
\text { de ciclovias (Banco Mundial, 2002); } \\
\text { - A distância aceitável para o uso da bicicleta tende a variar entre } 2 \text { e } 10 \mathrm{~km} \text {, de acordo com distintos } \\
\text { fatores, como o propósito da viagem. Em linhas gerais, considera-se } 8 \mathrm{~km} \text { um valor razoável para } \\
\text { expressar esse limite (Dill \& Voros, 2007); } \\
\text { - A promoç̃ão do uso da bicicleta precisa de trânsito seguro, confiável e direto. Aç̃oes mínimas incluem a } \\
\text { provisão de: infraestrutura segura e adequadamente segregada, rotas diretas sem grandes conflitos com } \\
\text { o trânsito automotor e bicicletários seguros para evitar roubos que prejudiquem a integração com o TP } \\
\text { (Adjei, 2010; Banco Mundial, 2002). }\end{array}$ \\
\hline $\begin{array}{l}\text { B3. Promover a integração da bicicleta com outros modais, como } \\
\text { trem e metrô, para seu uso nas viagens a trabalho e escolhas feitas } \\
\text { cotidianamente. }\end{array}$ & $\begin{array}{l}\text { - A oferta do TP não satisfaz as necessidades de mobilidade das pessoas, especialmente na última milha', } \\
\text { na qual a bicicleta pode contribuir como um sistema alimentador dos transportes públicos (Rietveld, } \\
\text { 2000). Uma adequada integração da bicicleta a estes tende a atrair mais usuários e a aumentar a } \\
\text { cobertura do sistema coletivo (TRB, 2005); } \\
\text { - No Rio de Janeiro, existem áreas com potencial uso de bicicleta integrado a outros modais, como metrô } \\
\text { ou trem, por conta da trama urbana interconectada, usos mistos e oferta de infraestrutura para ciclistas, } \\
\text { como os bairros da Tijuca e da Zona Sul. }\end{array}$ \\
\hline
\end{tabular}

Fonte: Elaboração própria.

Estratégias destinadas a melhorar a infraestrutura e os equipamentos para bicicletas (B)

As três estratégias contempladas nesta categoria pretendem incentivar o uso da bicicleta, propiciando condições mais seguras e de conectividade entre os pontos de interesse que se encontram a uma distância compatível com as características operacionais dessa modalidade (Tabela 3).

\section{Estratégias destinadas às condições} operacionais, à sinalização, à iluminação e à segurança dos pedestres (C)

Esta categoria incluiu quatro estratégias que buscam favorecer fluxos de pedestres com menos conflitos e melhorar as condições de segurança viária e pessoal. Considerando-se que muitos espectadores não moram

${ }^{1} \mathrm{O}$ chamado problema da última milha refere-se ao vazio de interconexão que tipicamente existe entre o serviço de transporte de longa e curta distância e que tem como consequência que a última (ou primeira) milha da viagem se realize em automóvel ou táxi desde o sistema de transporte principal ao destino final (ou vice-versa) (Lundlin, 2011). no bairro, preveem-se sinalização e equipamentos que favoreçam sua orientação (Tabela 4).

\section{Campanhas destinadas a promover modalidades sustentáveis e a desestimular o uso do automóvel (D)}

As estratégias destinam-se a divulgar e a conscientizar as pessoas quanto às vantagens comparativas do uso das modalidades sustentáveis em relação ao automóvel (Tabela 5).

\section{Estratégias dirigidas ao uso do solo e à promoção e marketing do bairro onde o evento se realiza (E)}

Com as estratégias E1 e E2, pretende-se promover atividades permanentes e temporárias na região com o propósito de gerar um ambiente seguro e ameno, mais propício aos MNM. As estratégias E3 e E4 são destinadas a promover a Tijuca como uma região propensa a realizar atividades de entretenimento, assim como de alojamento para visitantes (Tabela 6). 
Tabela 4 - Caracterização e justificativa das estratégias destinadas às condições operacionais, à sinalização, à iluminação e à segurança dos pedestres

\begin{tabular}{|c|c|}
\hline Estratégia & Justificativa \\
\hline $\begin{array}{l}\text { C1. Organizar os fluxos de pedestres por distintos caminhos por meio de placas e de } \\
\text { agentes sinalizadores que forneçam diferentes opções de percurso para os pedestres } \\
\text { até } 0 \text { estádio e demais atividades e serviços direcionados ao público. }\end{array}$ & $\begin{array}{l}\text { - Caminhos sem presença de aglomeraç̃oes são percebidos como mais seguros para } \\
\text { a caminhada até o estádio (de acordo com grupos focais e LTNZ, 2009). }\end{array}$ \\
\hline $\begin{array}{l}\text { C2. Melhorar a sinalização de orientação no entorno do estádio, fazendo uso de } \\
\text { diversos recursos que apresentem informações sobre os trajetos a pé até ele, prin- } \\
\text { cipalmente informando distâncias reais a serem percorridas e o tempo de viagem. } \\
\text { Recomenda-se que essa ação não seja feita apenas de forma temporária, mas tam- } \\
\text { bém aprimorando a sinalização fixa dos caminhos para pedestres. }\end{array}$ & $\begin{array}{l}\text { - A confiabilidade - facilidade com que os pedestres podem orientar seu desloca- } \\
\text { mento e a certeza de chegar ao destino e no horário - (LTNZ, 2009) apareceu } \\
\text { com grande destaque nos grupos focais para o modo a pé até o estádio; } \\
\text { - Os pedestres têm características diferentes dos outros usuários da via, por isso } \\
\text { devem-se tomar medidas específicas: canalizar os fluxos pedestres, realçar a } \\
\text { presença de pedestres, indicar as prioridades nas interseções (LTNZ, 2009). }\end{array}$ \\
\hline $\begin{array}{l}\text { C3. Melhorar a iluminação e a visibilidade, favorecendo a percepção de segurança } \\
\text { nos trajetos a pé, a fim de incentivar a presença de pessoas, em especial do público } \\
\text { feminino. }\end{array}$ & $\begin{array}{l}\text { - A sensação de vulnerabilidade, diante da possibilidade de crime, é um aspecto } \\
\text { importante para os pedestres (Austroads, 2013), podendo ser melhorado por meio } \\
\text { da iluminaccão e de medidas que favoreçam a visibilidade e um ambiente seguro } \\
\text { (LTNZ, 2009); } \\
\text { - Os grupos focais indicam que a segurança - de tráfego e urbana - é o aspecto } \\
\text { que mais condiciona a seleção de rotas, em especial no caso das mulheres. Existe } \\
\text { a preferência por caminhos com boa conectividade, pois eles facilitam a saída em } \\
\text { caso de emergência; } \\
\text { - A segurança de tráfego é um atributo muito importante, nesse sentido é necessário } \\
\text { contar com um desenho adequado de ruas e interseções (Austroads, 2013), assim } \\
\text { como a presença de dispositivos de controle de trânsito e sinalização. }\end{array}$ \\
\hline $\begin{array}{l}\text { C4. Procurar meios de expor a presença de policiamento ao público de forma pouco } \\
\text { ostensiva. }\end{array}$ & $\begin{array}{l}\text { - De acordo com os grupos focais: a imagem de um policiamento agressivo pode } \\
\text { causar maior sensação de insegurança nos espectadores que circulam pela região. } \\
\text { Diferentes pesquisas confirmam que a presença discreta do policiamento favorece } \\
\text { a ordem pública em grandes aglomerações (Stott et al., 2006); } \\
\text { - A vigilância é frequentemente citada na literatura como um dos fatores mais } \\
\text { influentes nas viagens a pé (Valenzuela-Montes \& Talavera-García, 2015). }\end{array}$ \\
\hline
\end{tabular}

Fonte: Elaboração própria.

Tabela 5 - Caracterização e justificativa das estratégias destinadas a promover modalidades sustentáveis e a desestimular 0 uso do automóvel

\begin{tabular}{|c|c|}
\hline Estratégia & Justificativa \\
\hline $\begin{array}{l}\text { D1. Divulgar a restrição de estacionar e circular o automóvel sem autorização } \\
\text { no entorno do estádio, reforçando as desvantagens comparativas do uso dessa } \\
\text { modalidade no megaevento. } \\
\text { D2. Criar campanhas de marketing que incentivem MNM na Tijuca, especialmente } \\
\text { focadas no público feminino e o de maior idade. Tais campanhas devem estar } \\
\text { acompanhadas de intervenções urbanas que incorporem um desenho de alta } \\
\text { qualidade do espaço público, assim como elementos que forneçam segurança, } \\
\text { encorajando a caminhada e o uso da bicicleta. }\end{array}$ & $\begin{array}{l}\text { - Apesar das restrições para estacionar e circular, 4,2\% das viagens com origem na } \\
\text { Tijuca para o evento foram realizadas por automóvel, e 10,5\%, de táxi, mostrando } \\
\text { que os modos motorizados de uso particular são uma opção atraente para as } \\
\text { viagens de curta distância nesse bairro, favorecidas pela presença de domicílios } \\
\text { com renda média e alta nessa área (IBGE, } 2010) \text {; } \\
\text { - A maioria dos espectadores entrevistados }(60,4 \%) \text { dispunha de automóvel. } \\
\text { A metade das pessoas que foram a pé afirmou dispor desse modo, das quais } \\
82 \% \text { alegaram que preferiram a caminhada devido às dificuldades para estacionar; } \\
\text { - Na Tijuca, as condições urbanas são positivas para viagens a pé: rede relativamente } \\
\text { interconectada, usos mistos do solo e presença de infraestrutura para pedestre } \\
\text { (Flórez et al., 2014); } \\
\text { - Verificou-se que as mulheres, os idosos e os turistas estão mais propensos a optar } \\
\text { por modos motorizados (táxi e metrô), mesmo estando próximos ao estádio; } \\
\text { - Quando avaliada a propensão a mudar do automóvel para modais mais } \\
\text { sustentáveis, observou-se que entre os usuários mais propensos a mudar estavam } \\
\text { aqueles localizados na Tijuca, área beneficiada pela proximidade e existência de } \\
\text { infraestrutura que incentiva a caminhada, e que teve um peso relativo (8,6\%) no } \\
\text { total das viagens. }\end{array}$ \\
\hline
\end{tabular}

Fonte: Elaboração própria. 
Tabela 6 - Caracterização e justificativa das estratégias dirigidas ao uso do solo e à promoção e marketing do bairro onde o evento se realiza

\begin{tabular}{|c|c|}
\hline Estratégia & Justificativa \\
\hline $\begin{array}{l}\text { El. Promover atividades temporárias de entretenimento, lazer e recreaccão dentro do } \\
\text { Maracanã ou no entorno, antes e depois de finalizado o evento, para ter um melhor } \\
\text { aproveitamento dos diversos modos de transporte, evitando o acúmulo de pessoas, } \\
\text { especialmente na sáida do evento. }\end{array}$ & $\begin{array}{l}\text { - Considerando que muitos espectadores preferem chegar com antecipacãão ( } 20 \% \text { com } \\
\text { três horas) e que, de acordo com os grupos focais, os pedestres avaliam como um fator } \\
\text { positivo da caminhada as condições de socialização, a identificação e a criação de um } \\
\text { ambiente festivo e de atividades locais serviriam não somente aos alojados na Tïuca, } \\
\text { mas também àqueles que chegam mais cedo, gerando, assim, condições favoráveis para } \\
\text { a caminhada; } \\
\text { - Em termos gerais, os espectadores subestimam os tempos de caminhada. Em média, } \\
\text { o tempo percebido é de } 10 \text { minutos menor ao efetivo para cada percurso (com base } \\
\text { em estimativas dos entrevistados). Isso pode ser explicado pelo ambiente festivo que } \\
\text { envolve o evento e torna o trajeto mais ameno. Tais atividades tendem a amenizar a } \\
\text { percepção do tempo no trajeto e na espera do evento, conforme indica Litman (2008) } \\
\text { para o caso do TP: os atributos qualitativos das viagens (como conforto, conveniência e } \\
\text { segurança) afetam o valor que os usuários atribuem ao tempo de viagem ou de espera, } \\
\text { o que se traduz em condições favoráveis. }\end{array}$ \\
\hline $\begin{array}{l}\text { E2. Fortalecer na Tïuca os usos de solo mistos por meio de políticas e de regulaccões } \\
\text { urbanas, bem como manter adensamento relativamente alto. }\end{array}$ & $\begin{array}{l}\text { - } 0 \text { planejamento do transporte e do uso do solo de forma integrada é uma ferramenta } \\
\text { muito forte para incentivar o uso de diferentes modalidades de transporte (Monzón, } \\
\text { 2005); } \\
\text { - A densidade influencia na mobilidade utilizada, tendendo a reduzir o uso do automóvel } \\
\text { à medida que esta aumenta (Rodrigues et al., 2014). Adicionalmente, o uso do solo é } \\
\text { um dos fatores que mais influenciam na mobilidade dos pedestres (Valenzuela-Montes } \\
\text { \& Talavera-García, 2015). A área de influência do estádio do Maracanã apresenta uma } \\
\text { diversidade de usos do solo, uma alta densidade e uma rede de caminhos relativa- } \\
\text { mente conectados, proporcionando um ambiente construído favorável para caminhar } \\
\text { (Flórez et al., 2014). }\end{array}$ \\
\hline $\begin{array}{l}\text { E3. Criar e promover uma "marca" Tïuca como um local de entretenimento diurno e alo- } \\
\text { jamento temporário por meio da organização de grupos vizinhos, taxistas, empresários e } \\
\text { líderes da Prefeitura. }\end{array}$ & $\begin{array}{l}\text { - Resultados dos questionários mostram que alguns espectadores não residentes se } \\
\text { alojam na Tïuca, apesar de não ser um dos setores turísticos da cidade; } \\
\text { - A promoção de uma marca no âmbito urbano leva à criação de estratégias que }\end{array}$ \\
\hline $\begin{array}{l}\text { E4 Abrir um site ou conceber um aplicativo com indicação das atividades lúdicas, aloja- } \\
\text { mentos, trajetos mais interessantes a pé e de bicicleta, inclusive sinalizando nas estações } \\
\text { de metrô, de trem e no entorno do estádio os lugares de interesse, de maneira a reforçar } \\
\text { a atratividade da Tïuca. }\end{array}$ & $\begin{array}{l}\text { convergem em um único conceito, sem deixar de lado a gestão dos recursos, a reputaç̃ão } \\
\text { do local e a sua imagem. A marca impulsiona a competitividade local para atrair turistas } \\
\text { e potenciais investidores, ao mesmo tempo que ajuda na regeneração urbana do local e } \\
\text { incrementa a qualidade de vida dos moradores (Dinnie, 2011); } \\
\text { - Considerando que a Tïuca é um bairro de usos mistos, intensa dinâmica urbana, } \\
\text { boa acessibilidade por meio de TP e da presença do estádio (condiç̃oes validadas pelos } \\
\text { grupos focais), é possível promover o local como zona de alojamento e atividades } \\
\text { urbanas. Durante os eventos no Maracanã, a Tijuca pode se posicionar como um bairro } \\
\text { de alojamento com acesso a pé e de bicicleta até o estádio. }\end{array}$ \\
\hline
\end{tabular}

Fonte: Elaboração própria.

\section{Avaliação das estratégias por meio de consulta a especialistas}

\section{Procedimento de consulta e processamento dos resultados}

Depois da determinação e classificação das estratégias, realizou-se uma consulta a profissionais (da Secretaria Municipal de Transportes do Rio de Janeiro, da Companhia de Engenharia de Tráfego e da Empresa Olímpica Municipal) dedicados à prática do planejamento e da gestão dos transportes, com atuação na elaboração e na execução do plano de transportes e trânsito durante os jogos da CC2013 e da CMF2014 realizados no Maracanã.

O objetivo da consulta foi garantir uma interação com os especialistas a fim de analisar a adequabilidade e validar as estratégias propostas, envolvendo um processo participativo, transparente e respaldado tecnicamente, permitindo convergir para um elenco de estratégias mais consolidado.

Dos especialistas consultados, dez deles confirmaram a sua participação, preenchendo uma tabela enviada por correio eletrônico para a avaliação das estratégias. 
Os especialistas avaliaram cada estratégia por meio de perguntas fechadas, com base em itens tipo-Likert (Boone \& Boone, 2012), para definir a importância, o grau de dificuldade e o horizonte de aplicação destas, ou escrevendo diretamente, no caso de consultas abertas (principais restrições e atores responsáveis). Nos itens tipo-Likert, transferem-se qualidades atitudinais em uma escala quantitativa para fins do processamento dos dados, mas, nesse caso, diferentemente da escala Likert, cada item é tratado como uma pergunta individual sem pretender combinar os resultados das respostas no momento da análise. Consequentemente, as medidas de tendência central devem ser a mediana ou a moda (Boone \& Boone, 2012).

0 grau de importância, que mede a relevância de implementar cada estratégia a fim de promover os MNM, foi avaliado por meio de uma escala de cinco níveis: 1 , sem importância; 2 , pouco importante; 3, indiferente; 4, importante; e 5, muito importante. Porém, o grau de dificuldade de implementar tais estratégias foi medido em apenas três níveis: 1, baixo; 2, moderado; e 3, alto. Antes de definir este último, os consultados deviam descrever as principais restrições de acordo com sete categorias: políticas; recursos (financeiros-custos e tempo); legais; técnicas; gerenciais e de planejamento; culturais (mudança de hábito e comportamento); ambientais e sociais (segurança).

Na Figura 1, apresentam-se os resultados obtidos (em porcentagens) com relação ao grau de importância que os especialistas outorgaram a cada estratégia.

Foram calculados a moda (Mo) para medir a tendência central dos dados e o intervalo (I) para medir a sua dispersão, na análise estatística referente à importância e à dificuldade de cada estratégia. Levando em conta essas análises, classificaram-se as estratégias a partir dos seguintes critérios:

1. A prioridade de aplicação das estratégias classificou-se em alta, moderada e baixa prioridade, de acordo com sua importância e dificuldade;

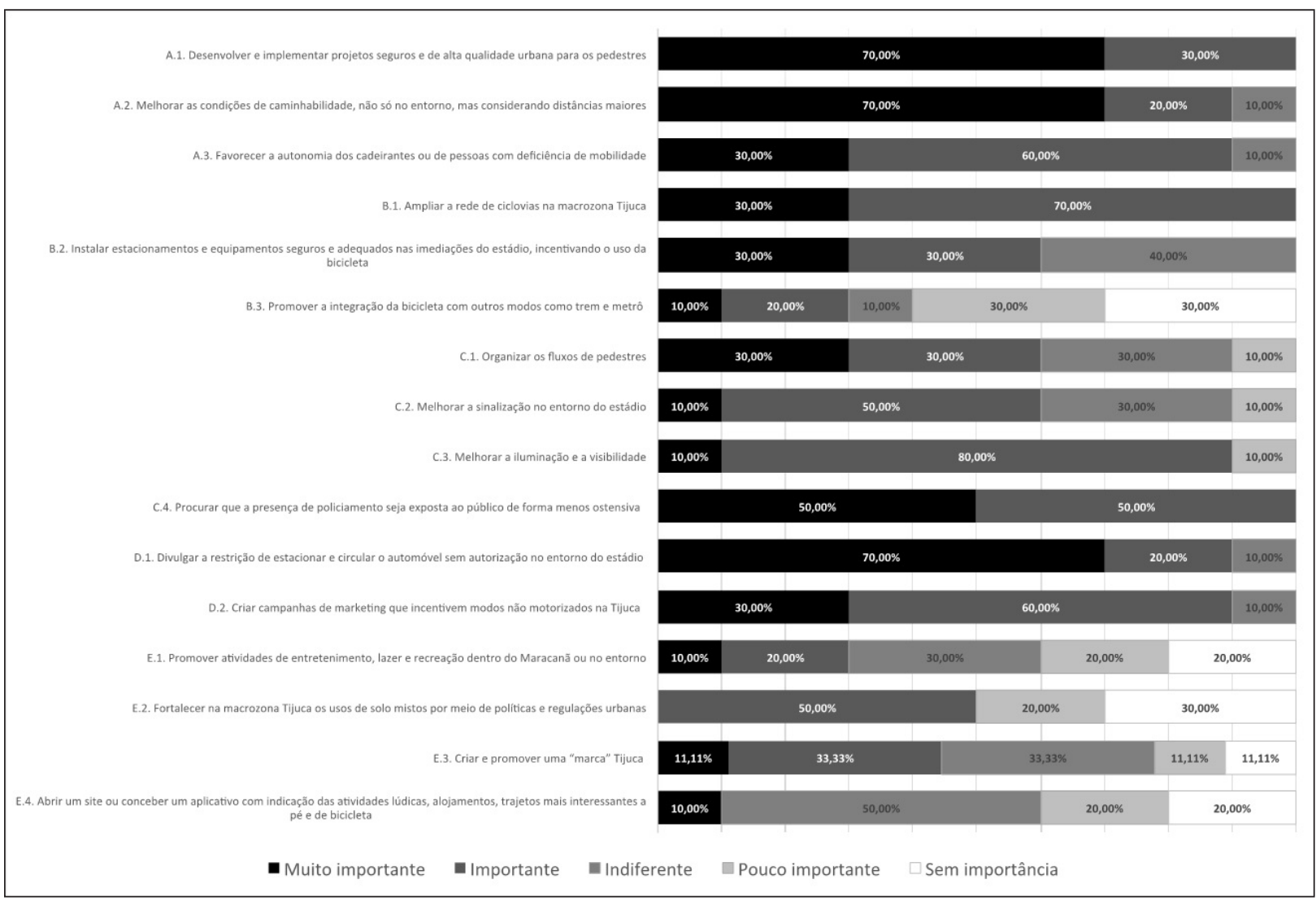

Figura 1 - Grau de importância das estratégias segundo os especialistas Fonte: Elaboração própria. 
2. A importância aumentou com o valor da Mo, portanto considerou-se que as estratégias com moda igual ou maior a 4 eram as que tinham maior importância. 0 intervalo indicou a dispersão entre os dados; consequentemente, para menores valores de I, obteve-se maior consenso na valoração feita pelos especialistas;

3. O grau de dificuldade para a implantação de cada estratégia foi medido pela moda dos valores e do intervalo. Para valores da Mo igual a 1 , classificou-se como baixa dificuldade; igual a 2, moderada; e valores de 3, como de alta dificuldade. Entretanto, todas as estratégias obtiveram valores de 1 e 2 . Com relação ao intervalo, os valores observados não apresentaram um comportamento que orientasse a classificação dos resultados.

Considerando estes aspectos, foram definidos os critérios estabelecidos na Tabela 7 e os resultados são mostrados na Tabela 8.

Adicionalmente, realizou-se uma análise quanto ao horizonte de aplicação e aos atores responsáveis, enfatizando as estratégias consideradas mais importantes pelos especialistas. Para o horizonte de aplicação das estratégias, foi considerada a porcentagem de respostas dos consultados, com as estratégias a serem implementadas, no curto (dois anos) ou médio prazo (cinco anos), compreendendo todas aquelas em que $60 \%$ ou mais dos entrevistados concordaram que a aplicação deveria ser em algum desses períodos. Nos casos em que o respectivo percentual variou entre $50 \%$ até $60 \%$, entendeu-se que existia uma situação indefinida para o horizonte de aplicação.
Prioridade e natureza das restrições para a implantação bem-sucedida das estratégias

Com base nos resultados (Tabela 8), verificou-se um alto consenso entre os especialistas sobre a identificação das estratégias de alta prioridade, pois a dispersão entre as respostas foi baixa $(\mathrm{I} \leq 2)$, além de que todas as estratégias apresentaram um baixo nível de dificuldade de implantação. 0 grupo de estratégias com moderada prioridade teve valores da moda de 3 e 4. Em geral, a dispersão entre as opiniões dos especialistas foi maior ( $\mathrm{I}=3$, com uma exceção), enquanto o nível de dificuldade se encontrou entre baixo e moderado.

Por fim, as estratégias de baixa prioridade, além de contar com menores valores da moda, tiveram a maior dispersão de respostas ( $(=4)$ e, portanto, mostraram menor consistência e consenso entre os especialistas, apesar de manter o nível de dificuldade entre moderado e baixo.

Adicionalmente, ao se observar a Figura 1, verificou-se que, em algumas estratégias, as opiniões sobre o grau de importância encontraram-se divididas ( $50 \%$ importante e $50 \%$ pouco importante), como C4 e E2, ou inclusive no caso da E4, em que 50\% dos consultados opinaram que era indiferente, o que sugere um maior aprofundamento desses casos em pesquisas posteriores.

Com relação às categorias das estratégias, constatou-se que todas as orientadas a infraestrutura e equipamentos para pedestres e cadeirantes (A), assim como as que estão direcionadas a promover as modalidades mais sustentáveis (D), são consideradas de alta prioridade. Quanto às estratégias orientadas às condições operacionais, à sinalização, à iluminação $e$ à segurança (C), C2 e C3 foram consideradas de alta prioridade, $\mathrm{C} 1$, de média, e $\mathrm{C} 4$, como de baixa

Tabela 7 - Critérios de classificação das estratégias segundo sua prioridade

\begin{tabular}{|c|c|c|c|c|c|c|}
\hline \multirow{2}{*}{ Prioridade } & \multicolumn{3}{|c|}{ Importância } & \multicolumn{3}{|c|}{ Dificuldade } \\
\hline & Grau & Mo: Moda & I: Intervalo & Grau & Mo: Moda & I: Intervalo \\
\hline Alta & Alta & $\geq 4$ & $\leq 2$ & Baixa & 1 & $0-2$ \\
\hline Média & Média & $3-4$ & $2-3$ & \multirow{2}{*}{ Baixa ou Moderada } & \multirow{2}{*}{$\leq 2$} & \multirow{2}{*}{$1-2$} \\
\hline Baixa & Baixa & $\leq 3$ & $>3$ & & & \\
\hline
\end{tabular}

Fonte: Elaboração própria. 
Tabela 8 - Resultados da análise estatistica e classificação das estratégias

\begin{tabular}{|c|c|c|c|c|c|c|}
\hline \multirow[t]{2}{*}{ Identificação das estratégias } & \multirow{2}{*}{$\begin{array}{l}\text { Grau de } \\
\text { importância }\end{array}$} & \multicolumn{2}{|c|}{$\begin{array}{l}\text { Análise estatistica: } \\
\text { resultados da importância }\end{array}$} & \multirow{2}{*}{$\begin{array}{l}\text { Grau de } \\
\text { dificuldade }\end{array}$} & \multicolumn{2}{|c|}{$\begin{array}{l}\text { Análise estatística: } \\
\text { resultados da dificuldade }\end{array}$} \\
\hline & & Moda & Intervalo & & Moda & Intervalo \\
\hline \multicolumn{7}{|l|}{ ALTA PRIORIDADE } \\
\hline $\begin{array}{l}\text { Al Desenvolver e implementar projetos seguros e de alta } \\
\text { qualidade urbana para os pedestres. }\end{array}$ & Alto & 5,00 & 1 & Baixo & 1,00 & 2 \\
\hline A2 Melhorar as condições de caminhabilidade. & Alto & 5,00 & 2 & Baixo & 1,00 & 2 \\
\hline A3 Favorecer a autonomia dos cadeirantes. & Alto & 4,00 & 1 & Baixo & 1,00 & 2 \\
\hline C2 Melhorar a sinalização. & Alto & 4,00 & 2 & Baixo & 1,00 & 0 \\
\hline C3 Melhorar a iluminação e a visibilidade. & Alto & 4,00 & 1 & Baixo & 1,00 & 1 \\
\hline DI Divulgar a restrição de estacionar e circular o automóvel. & Alto & 5,00 & 2 & Baixo & 1,00 & 1 \\
\hline $\begin{array}{l}\text { D2 Criar campanhas de marketing que incentivem MNM } \\
\text { na Tïuca. }\end{array}$ & Alto & 4,00 & 2 & Baixo & 1,00 & 1 \\
\hline \multicolumn{7}{|l|}{ MODERADA PRIORIDADE } \\
\hline BI Ampliar a rede de ciclovias na Tïuca. & Moderado & 3,00 & 3 & Moderado & 2,00 & 2 \\
\hline B2 Instalar estacionamentos e equipamentos seguros. & Moderado & 4,00 & 3 & Baixo & 1,00 & 2 \\
\hline B3 Promover a integração da bicicleta com outros modos. & Moderado & 4,00 & 3 & Moderado & 2,00 & 2 \\
\hline Cl Organizar os fluxos de pedestres. & Moderado & 3,00 & 2 & Baixo & 1,00 & 1 \\
\hline $\begin{array}{l}\text { El Promover atividades de entretenimento, lazer e } \\
\text { recreação. }\end{array}$ & Moderado & 4,00 & 3 & Baixo & 1,00 & 2 \\
\hline \multicolumn{7}{|l|}{ BAIXA PRIORIDADE } \\
\hline $\begin{array}{l}\text { C4 Procurar meios de expor a presença de policiamento de } \\
\text { forma menos ostensiva. }\end{array}$ & Baixo & 2,00 & 4 & Baixo & 1,00 & 2 \\
\hline E2 Fortalecer na Tïuca os usos de solo mistos. & Baixo & 3,00 & 4 & Moderado & 2,00 & 2 \\
\hline E3 Criar e promover uma "marca" Tïuca. & Baixo & 3,00 & 4 & Moderado & 2,00 & 1 \\
\hline E4 Abrir um site ou conceber um aplicativo. & Baixo & 3,00 & 4 & Baixo & 1,00 & 1 \\
\hline
\end{tabular}

Fonte: Elaboração própria.

prioridade. Todas as estratégias agrupadas na categoria $\mathrm{B}$, destinadas a infraestrutura e ao equipamento para bicicletas, foram contempladas como de prioridade moderada. Uma das estratégias dirigidas ao uso do solo e à promoção e marketing do bairro considerou-se de prioridade moderada (E1), e as outras três, de baixa prioridade (E2, E3 e E4).

No que diz respeito às estratégias de alta prioridade, as restrições mais frequentes estavam associadas à falta de recursos, às deficiências de gerência e de planejamento e a aspectos políticos. No que se refere aos recursos, citaram-se os econômicos e financeiros para a execução de obras e compra de mobiliário urbano. Quanto às deficiências de gerência e de planejamento, foi citada, principalmente, a falta de projetos urbanos (mobilidade, tráfego e desenho urbano), assim como a necessidade de investimento e de fiscalização por parte dos órgãos públicos. Por último, as restrições políticas foram associadas à falta de comprometimento do poder público com projetos relacionados à promoção de MNM.

\section{Horizonte de aplicação e atores responsáveis}

Em termos gerais, observou-se que existe uma tendência à aplicação das medidas no curto prazo. A maioria dos especialistas (entre 70 e 100\%) considerou que, com exceção da A2, as seis demais estratégias de alta prioridade podiam realizar-se no curto prazo. 
Quanto aos atores responsáveis pela implantação das estratégias de maior prioridade, os especialistas, apesar de destacarem o papel da Prefeitura do Rio de Janeiro, incluíram o Governo do Estado do Rio de Janeiro, as operadoras dos transportes, os organizadores do evento, a mídia e a sociedade civil.

Os organizadores do evento passaram a ter um papel muito importante nas estratégias sugeridas, as quais, geralmente, estão associadas ao entorno do megaevento. Essa característica envolve, na maioria dos casos, um esforço conjunto de atores locais. Os meios de comunicação também tiveram um papel importante nas estratégias dirigidas à divulgação e à promoção de ações de conscientização e de incentivo a comportamentos e escolhas modais compatíveis com modalidades sustentáveis.

Ressalta-se ainda que a presença de diferentes atores na implantação de cada estratégia exige um esforço de articulação e de integração, que não tem sido comum no marco institucional das cidades e, principalmente, das metrópoles brasileiras, representando um desafio para a administração pública.

\section{Conclusões}

As 16 estratégias propostas contaram com respaldo teórico e prático, já que, além de terem sido identificadas a partir de consulta ao estado da arte, foram também extraídas dos resultados das opiniões de mais de 1.000 participantes e, ainda, avaliadas por especialistas.

De acordo com os especialistas consultados, todas as estratégias recomendadas neste artigo para incentivar as viagens não motorizadas tiveram baixo ou moderado nível de dificuldade para a sua implantação. Nesse sentido, representam uma boa opção para melhorar a qualidade urbana de certos setores da cidade e para promover a mobilidade sustentável com ações de baixo a moderado custo e de baixa complexidade técnica, o que se torna mais evidente ao se comparar com os requerimentos técnicos e custos de investimentos associados a ações dirigidas a infraestruturas e serviços destinados ao transporte motorizado.

As estratégias propostas destinam-se às áreas adjacentes ao estádio do Maracanã e estendem-se à Grande Tijuca. Não obstante, elas poderiam ser contempladas em outras zonas da RMRJ que contêm infraestrutura e instalações esportivas de grande porte e que se localizam em bairros com condições potenciais às viagens a pé e de bicicleta.

Com a aplicação das estratégias propostas indiretamente, incentiva-se o uso do TP, ao melhorar a qualidade dos trajetos para os pedestres e cadeirantes desde as paradas e estações dos sistemas coletivos até as instalações esportivas, assim como com outros geradores de viagens. Ainda assim, recomenda-se que, em prol de promover uma mobilidade mais sustentável na RMRJ, também se apliquem, de forma conjunta, medidas a favor do TP e de desestímulo ao uso do automóvel.

As estratégias consideradas de alta prioridade dirigem-se, principalmente, a melhorias de infraestrutura e de equipamentos para os pedestres e cadeirantes, incluindo na iluminação, na sinalização, bem como campanhas de divulgação e de conscientização que incentivem o uso dos MNM e reforcem as restrições de acessar e estacionar no entorno do estádio. Com relação às medidas destinadas a estimular o uso da bicicleta, elas são consideradas de moderada prioridade. Ainda, as estratégias mais orientadas ao uso do solo e à promoção do bairro são consideradas de moderada a baixa prioridade, o que pode significar uma tendência dos especialistas em valorizarem as ações mais concretas na melhoria da infraestrutura para os pedestres e nas campanhas de incentivo ao uso dos modos sustentáveis.

Das sete estratégias destacadas pelos especialistas, seis poderiam ser executadas no curto prazo, e todas com baixo grau de dificuldade de implantação, favorecendo a sua aplicação. Mesmo assim, isso ainda não ocorreu, provavelmente por restrições, como a atuação coordenada entre os atores intervenientes.

É válido ressaltar que as 16 estratégias resultantes configuram uma base de conhecimento que deve servir de referência e de estímulo para novos aprofundamentos e aperfeiçoamentos. Destaca-se também que os megaeventos deveriam ser vistos como oportunidades para se construir uma cultura de planejamento e de operação segundo uma concepção intersetorial e integrada, valorizando a pesquisa de campo para capturar as especificidades locais e as necessidades percebidas pelos usuários do evento. Acrescenta-se a necessidade de se garantir um processo de decisão mais transparente e participativo que contribua para a promoção de um sistema de transporte mais digno para a população do Rio de Janeiro e seus visitantes. Ressalta-se ainda que as mudanças de 
comportamento dos usuários em suas viagens, durante os megaeventos, podem permanecer e ser estendidas a seus deslocamentos cotidianos (Parkes et al., 2016). Por último, na hora de formular e de implementar estratégias, os governos locais devem considerar e garantir uma visão de conjunto da metrópole. Tal como indica Sassen (2007), é necessário que as autoridades assumam competências sob um marco mais amplo e inovador de governança. Assim, Varela (2015) prevê que as autoridades deverão enfrentar o desafio que representa a coordenação e a articulação entre os atores envolvidos e assumir competências e funções, como o marketing urbano, as associações público-privadas, a gestão do conhecimento, entre outras, garantindo uma visão que responda à dinâmica da região metropolitana.

\section{Agradecimentos}

Ao apoio do CNPq e da Rede Ibero-Americana de Estudo em Polos Geradores de Viagens; aos especialistas da Secretaria Municipal de Transportes do Rio de Janeiro, da Companhia de Engenharia de Tráfego e da Empresa Olímpica Municipal, que contribuíram na validação dos resultados desta pesquisa.

\section{Referências}

Adjei, E. (2010). Multi-modal urban transport: integrating non-motorized and bus transport (Dissertação de mestrado). International Institute for Geo-information Science and Earth Observation, The Netherlands.

America Walks \& Sam Schwartz Engineering. (2012). Steps to a walkable community a guide for citizens, planners, and engineers. Portland: America Walks \& Sam Schwartz Engineering.

Armazém de Dados. (2016). Evolução da extensão de ciclovias, por áreas de planejamento: 1990-2011. Rio de Janeiro: Armazém de Dados. Recuperado em 26 de fevereiro de 2016, de http://www.armazemdedados.rio.rj.gov.br

Austroads. (2013). Guide information for pedestrian facilities. Sydney: Austroads.

Banco Mundial. (2002). El papel del transporte no motorizado. In Banco Mundial. Ciudades en movimiento: revisión de la estrategia de transporte urbano del Banco Mundial (pp. 155-166). Washington: Banco Mundial.

Boone, H. N., Jr., \& Boone, D. A. (2012). Analyzing likert data. Journal of Extension, 50(2), 1-5.

Bovy, H. (2007). Transport and mobility management challenges for the world largest mega-event: 1992 to 2012 Summer Olympic Games. Berkeley: University of California. Recuperado em 26 de fevereiro de 2016, de http://www. mobility-bovy.ch/resources/16.BERKELEY-07.pdf

Cruz, O., No., Moreira, R. M., \& Sucena, L. F. M. (2002). Grupos Focais e Pesquisa Social Qualitativa: o debate orientado como técnica de investigação. In Anais do XIII Encontro da Associação Brasileira de Estudos Populacionais. Ouro Preto.

Dill, J., \& Voros, K. (2007). Factors affecting bicycling demand: initial survey findings from the Portland, Oregon Region. Transportation Research Record, 2031, 9-17. http:// dx.doi.org/10.3141/2031-02.

Dinnie, K. (2011). Introduction to the theory of city branding. In K. Dinnie (Ed.), City branding: theory and cases (pp. 3-7). Hampshire: Palgrave Macmillan. http:// dx.doi.org/10.1057/9780230294790_1.

Flórez, J., Muniz, J., \& Portugal, L. (2014). Pedestrian quality of service: lessons from Maracanã stadium. Procedia: Social and Behavioral Sciences, 160, 130-139. http://dx.doi. org/10.1016/j.sbspro.2014.12.124.

Instituto Brasileiro de Geografia e Estatística - IBGE. (2010). Censo 2010. Rio de Janeiro: IBGE. Recuperado em 3 de março de 2016, de http://censo2010.ibge.gov.br/en/

Land Transport New Zealand - LTNZ. (2009). Pedestrian planning and design guide. Wellington: NZ Transport Agency.

Litman, T. (2008). Valuing transit service quality improvements. Journal of Public Transportation, 11(2), 43-63. http:// dx.doi.org/10.5038/2375-0901.11.2.3.

Lundlin, M. (Ed.) (2011). High Efficient and Reliable Arrangements for CrossModal Transport (HERMES): collaborative project small of medium-scale focused research project. Brussels: European Commission.

Machado, M. H., \& Lima, J. P. (2015). Avaliação multicritério da acessibilidade de pessoas com mobilidade reduzida: um estudo na região central de Itajubá. urbe. Revista Brasileira de Gestão Urbana, 7(3), 368-382. http://dx.doi. org/10.1590/2175-3369.007.003.A008. 
Malhado, A. C., \& Rothfuss, R. (2013). Transporting 2014 FIFA World Cup to sustainability: exploring residents' and tourists' attitudes and behaviours. Journal of Policy Research in Tourism, Leisure and Events, 5(3), 252-269. http://dx.doi.org/10.1080/19407963.2013.801159.

Malhotra, N. K. (2012). Pesquisa de marketing: uma orientação aplicada (6a ed., 735 p.). Porto Alegre: Bookman.

Monzón, A. (2005). Gestión del transporte metropolitano. In E. Rojas, J. Cuadrado-Roura, \& J. Fernández Güell (Eds.), Gobernar las metrópolis (pp. 409-472). Washington: Banco Interamericano de Desarrollo.

Observatório das Metrópoles - ODM. (2013). Evolução da frota de automóveis e motos no Brasil 2001-2012. Rio de Janeiro: ODM. Recuperado em 20 de março de 2016, de http://www.observatoriodasmetropoles.net/download/ auto_motos2013.pdf

Parkes, S., Jopson, A., \& Marsden, G. (2016). Understanding travel behaviour change during mega-events: lessons from the London 2012 Games. Transportation Research Part A, Policy and Practice, 92, 104-119. http://dx.doi. org/10.1016/j.tra.2016.07.006.

Portugal, L., Flórez, J., Escobar, N., Muniz, J., Pereira, L. \& Cardoso, B. (2014) Caracterização dos usuários e das viagens ao Estádio do Maracanã na Copa das Confederações de 2013: indicativos para megaeventos futuros. Revista dos Transportes Públicos, 36, 57-81.

Rietveld, P. (2000). Non-motorized modes in transport systems: a multimodal chain perspective for The Netherlands. Transportation Research Part D, Transport and Environment, 5(1), 31-36. http://dx.doi.org/10.1016/ S1361-9209(99)00022-X.

Rio de Janeiro. Prefeitura - PRJ. (2013). Plano Estratégico da Prefeitura do Rio de Janeiro: pós 2016 O Rio mais integrado e competitivo: 2013-2016. Rio de Janeiro: PRJ. Recuperado em 20 de outubro de 2015, de http://200.141.78.79/ dlstatic/10112/2753734/DLFE241955.pdf/Planejamen toestrategico2.0.1.3.2.0.1.6.pdf

Rio de Janeiro. Secretaria de Estado de Transportes SETRANS. (2015). Plano diretor de transporte da região metropolitana do Rio de Janeiro 2015. Rio de Janeiro: SETRANS.

Rio de Janeiro. Prefeitura - PRJ. (2016). Ciclovias, ciclofaixas e faixas compartilhadas: obras e projetos 2015/16. Rio de
Janeiro: PRJ. Recuperado em em 20 de março de 2016, de http://www.rio.rj.gov.br/dlstatic/10112/91265/4133646/ relacaodeprojetoscicloviasPAGINASMAC16115.pdf

Rodrigues, A., Flórez, J., Frenkel, D., \& Portugal, L. (2014). Indicadores do desenho urbano e sua relação com a propensão a caminhada. Journal of Transport Literature, 8(3), 62-88. http://dx.doi.org/10.1590/S2238-10312014000300004.

Sassen, S. (2007). El reposicionamiento de las ciudades y regiones urbanas en una economía global: ampliando las opciones de política y gobernanza. Revista Latinoamericana de Estudios Urbano Regionales, 33(100), 9-34. http://dx.doi. org/10.4067/S0250-71612007000300002.

Scheiner, J. (2010). Interrelations between travel mode choice and trip distance: trends in Germany 1976-2002. Journal of Transport Geography, 18(1), 75-84. http://dx.doi. org/10.1016/j.jtrangeo.2009.01.001.

Schneider, R. J. (2011). Understanding sustainable transportation choices: shifting routine automobile travel to walking and bicycling (Tese de doutorado). University of California, Berkeley.

Stott, C., Adang, O., Livingstone, A., \& Schreiber, M. (2006). Policing, crowd dynamics and public order at Euro2004. London: U.K. Home Office. Unpublished report.

Transportation Research Board - TRB. (2005). Integration of bicycles and transit: a synthesis of transit practice. Washington: TRB.

Valenzuela-Montes, L. M., \& Talavera-García, R. (2015). Entornos de movilidad peatonal: una revisión de enfoques, factores y condicionantes. Revista Latinoamericana de Estudios Urbano Regionales, 41(123), 5-27. http://dx.doi. org/10.4067/S0250-71612015000300001.

Varela, E. (2015). Nuevos roles de los gobiernos locales en la implementación de políticas públicas. Gobernabilidad territorial y competitividad global. Revista Latinoamericana de Estudios Urbano Regionales, 41(123), 213-237. http:// dx.doi.org/10.4067/S0250-71612015000300009.

Waiselfisz, J. (2013). Mapa da violência 2013: acidentes de trânsito e motocicletas. Rio de Janeiro: Centro de Brasileiro de Estudos Latino-Americanos.

Recebido: Nov. 02, 2016

Aprovado: Set. 12, 2017 